\title{
Educação a distância em Moçambique: perspectivas para a inclusão da população no ensino superior
}

\author{
Distance education in Mozambique: perspectives for \\ inclusion of the population in higher education
}

\author{
Aires Bonifacio MombassA (iDa \\ EUCIDIO PIMENTA ARRUDA id b
}

\section{Resumo}

Este artigo tem por objetivo discutir as perspectivas de inclusão social, econômica e educacional que a Educação a Distância (EaD) apresenta a Moçambique, na perspectiva de proporcionar, em curto prazo, possibilidade de aumento da idade média de formação da população moçambicana em níveis da educação primária, da educação secundária e do ensino superior. A metodologia utilizada baseou-se em levantamento bibliográfico acerca de autores conceituais em EaD, dados estatísticos e políticas públicas de Moçambique, bem como autores do país que se debruçaram sobre esse assunto nos últimos anos. Observa-se que Moçambique apresenta hoje altas taxas de analfabetismo (perto de 50\%) e baixo índice de formação em nível médio e superior (respectivamente cerca de 13\% e menos de 1\%). De maneira a diminuir distâncias em tempos e espaços formativos e proporcionar ao país um crescimento mais acelerado dos níveis de formação, compreendemos que a modalidade EaD seria a mais adequada para atender as demandas e desafios hoje postos ao país. Torna-se ainda mais pertinente quando se observa que a EaD cresceu significativamente em Moçambique, mas ainda alcança um número relativamente baixo de alunos, sobretudo no ensino superior, configurando-se, portanto, uma modalidade de formação desafiadora e, ao mesmo tempo, capaz de proporcionar um grande salto educacional e inclusivo em Moçambique.

Palavras-chave: Inclusão educacional. Educação a Distância. Políticas públicas. Moçambique.

\footnotetext{
a Universidade Eduardo Mondlane (UEM), Maputo, Moçambique. Doutorando em Educação, e-mail: mombassaairez@gmail.com

b Universidade Federal de Minas Gerais (UFMG), Belo Horizonte, MG, Brasil. Doutor em Educação, email: eucidio@ufmg.br
} 


\begin{abstract}
This article aims to discuss the perspectives of social, economic and educational inclusion that Distance Education (EAD) presents to Mozambique, with a view to providing, in the short term, the possibility of expanding the average age of training of the Mozambican population at primary education, secondary education and higher education. The methodology used was based on a bibliographical survey about conceptual authors in EaD, statistical data and public policies of Mozambique, as well as authors from the country who have studied this subject in recent years. It is observed that Mozambique today has high rates of illiteracy (close to 50\%) and a low level of education at the middle and higher levels (respectively about 13\% and less than 1\%). In order to reduce distances in times and formative spaces and to provide the country with a faster growth of training levels, we understand that the EAD modality would be the most adequate to meet the demands and challenges facing the country today. It is all the more pertinent when it is observed that EaD has grown significantly in the country, but still reaches a relatively low number of students, especially in higher education, therefore, a form of training that is challenging and at the same time capable to provide a major educational and inclusive leap in Mozambique.
\end{abstract}

Keywords: Educational Inclusion. Distance Education. Public Policies. Mozambique.

\title{
Introdução
}

Moçambique é um país africano que tem se destacado na contemporaneidade pelo grande investimento na utilização e desenvolvimento de tecnologias digitais de informação e comunicação (TDIC) nos setores econômicos e sociais. Desde $2000^{1}$ há um movimento governamental que visa introduzir reformas no setor público, com vistas à adoção de TDIC, cujos resultados esperados estão vinculados à melhoria dos serviços públicos.

A nível da educação superior, data de 2001 as primeiras iniciativas em EaD como política nacional de formação no país, a partir da criação da Comissão Instaladora do Instituto Nacional de Educação a Distância (CIINED) (MOORE e PEREIRA, 2007). Some-se a isso a introdução dos conteúdos sobre as tecnologias no currículo do ensino secundário a partir de 2005, por meio do Programa de Ensino Secundário a Distância (PESD), conforme histórico do Ministério de Educação e Desenvolvimento Humano de Moçambique.

\footnotetext{
${ }^{1}$ Conforme Zimba e Muller (2010), acredita-se que esse ano assinala-se a provável primeira experiência de organização da ciência e tecnologia pelo Estado Moçambicano. 
A Educação a Distância atualmente é reconhecida pelo governo moçambicano como uma das estratégias comprovadas para minimizar as assimetrias regionais em Moçambique e, por conseguinte, promover inclusão social, econômica e educacional a um contingente significativo da população.

Há um certo entendimento de que as condições econômicas nas quais passa Moçambique (e o restante do mundo) faz com que a educação presencial não seja eficaz e efetiva, em curto e médio prazos, para oferecer oportunidades formativas às populações que vivem distante dos grandes centros urbanos, sobretudo porque grande parte da população de Moçambique vive em zonas rurais. Dessa forma, o governo moçambicano tem adotado a $\mathrm{EaD}$ como estratégia para operacionalizar as políticas públicas de educação.

Salienta-se ainda que Moçambique, assim como muitos países africanos, possui um histórico marcado por inúmeros conflitos sociais, políticos e econômicos que constituiu grande dificuldade para a constituição de sistemas educacionais efetivos e eficazes, fazendo com que mais de $45 \%$ da população do país seja analfabeta, sendo cerca de 75\% mulheres (MOÇAMBIQUE, 2015a).

Ao se analisar as demandas em um mundo globalizado e em constante transformação, que complexifica cada vez mais o trabalho e a educação, observa-se que o país, literalmente possui pouco tempo para recuperar as dificuldades em oferecer massivamente Educação em todos os níveis para a população, com vistas ao atendimento às demandas formativas contemporâneas. Dessa forma, compreendemos que a Educação a Distância emerge como uma política prioritária que promove, em níveis ainda não precedentes, uma ampliação substancial e veloz da formação básica da população moçambicana.

Nesse sentido, esse artigo procura discutir as perspectivas de inclusão socioeconômica da população moçambicana por meio da ampliação de políticas de EaD massivas, possibilitando a retirada do país de uma situação pouco confortável no que diz respeito à formação geral de sua população em todos os níveis: educação primária, educação secundária e ensino superior. 
Diferente de países com dimensões territoriais maiores, como o Brasil, o desafio de Moçambique está mais vinculado às dificuldades enfrentadas para formar formadores em períodos curtos, que deem conta das demandas nacionais por educação primária e secundária, do que as grandes distâncias entre centros formadores, escolas e população.

Em uma sociedade global cujas tecnologias digitais desenvolvem-se de forma cada vez mais veloz e cujas demandas de trabalho tornam-se cada vez mais complexas, Moçambique encontra-se em uma situação de extrema necessidade de participar dos compartilhamentos de saberes e produções mundiais, sob o risco de ver aprofundarse as desigualdades sociais, econômicas e educacionais.

Conforme poderá ser visto ao longo do texto, apesar dessa necessidade formativa apresentada, o país, sobretudo os centros de formação em nível superior, anunciam-se como lócus de resistência à EaD, seja na dimensão do desenvolvimento de um sistema de formação a distância para formação em massa (no sentido de se formar muitos moçambicanos), seja nas reconfigurações do trabalho e das práticas pedagógicas dos professores (MOMBASSA, 2003).

A metodologia adotada para o desenvolvimento do artigo baseia-se em revisão bibliográfica, sobretudo de autores moçambicanos, que consistiu na identificação, análise e sistematização dos dados e discussões que permitem-nos compreender o papel da EaD como fomentadora de ampliação do acesso à educação formal e, por conseguinte, ampliação dos níveis educacionais de Moçambique.

E como forma de compreender alguns indicadores dessa modalidade de educação, optamos por fazer um recorte dos últimos cinco anos (2013-2017). Consideramos a escolha desses últimos cinco anos porque foram os anos em que se registaram maior crescimento da oferta dos programas dessa modalidade de educação em quase todos os subsistemas de ensino e, portanto, ao resgatar alguns argumentos que nos possibilite entender o processo de inserção dessa modalidade de educação, estaremos a contribuir para ampliação e discussão teórica sobre as perspectivas de inclusão social e econômica da população moçambicana por meio da EaD. 


\section{Educação a distância em Moçambique: Histórias e perspectivas amplificadoras do acesso à educação}

A agenda 2030 para o desenvolvimento sustentável elaborado pelas Nações Unidas (ONU), em seu objetivo quatro, sublinha que os países devem assegurar a educação inclusiva e equitativa e de qualidade, e promover oportunidades de aprendizagem ao longo da vida para todas e todos.

Conforme aponta Mombassa e Arruda (2018), a história de Moçambique, sobretudo posterior ao domínio português e após a independência, foi permeada por conflitos, guerras e circunstâncias que dificultaram o desenvolvimento de políticas educacionais duradouras.

No período pós-colonial (1975 em diante), houve nacionalização do ensino de Moçambique em um contexto de falta de recursos financeiros para atendimento até mesmo aos níveis pré-coloniais. Dados do Relatório do Programa das Nações Unidas para o Desenvolvimento (PNUD) de 2001 mostram que em junho de 1975, momento da independência do país, Moçambique possuía apenas $7 \%$ da população com alguma experiência educacional - o que demonstra o caráter inclusivo que o acesso à educação poderia promover no país.

De acordo com Mombassa e Arruda (2018) e Ngoenha (1999), o governo moçambicano não possui recursos humanos qualificados e infraestrutura, resultando na oferta de uma educação pública com níveis de qualidade inferiores ao ensino colonial português.

Paralelo a esse problema, o país enfrentou uma guerra civil iniciada em 1976, finalizada apenas em 1992, descontruindo ainda mais o já frágil sistema educacional nacional. Conforme afirma Hanlon (1997), a guerra civil atingiu principalmente as zonas rurais, com escolas e hospitais bombardeados, professores e alunos raptados, infraestrutura destruída. Estima-se que cerca de 1 milhão de pessoas tinham morrido, 1,7 milhões se tenha refugiado nos países vizinhos e pelo menos 3 milhões estivessem deslocados das suas regiões de origem.

A maioria dos intelectuais e de profissionais especializados não regressaram ao país após 1992 e o número exacerbado de minas terrestres criou inúmeras dificuldades 
de repatriação, devido à impossibilidade de se destinar locais de residência com segurança.

As dificuldades enfrentadas ao longo da luta de libertação nacional demonstraram à população a necessidade de se investir maciçamente na educação, como forma de elevar os níveis de vida populacional, conforme apontamentos publicados pela AfriMAP2 e pela Open Society Iniciative for Souther Africa.

Nessa perspectiva, Neeleman e Nhavoto (2003) demonstram que, em 1977, a Frente Única de Libertação de Moçambique (Frelimo), que estava à frente do comando do país, indicou o encerramento das iniciativas em formação da população que fizessem uso de instituições internacionais, sobretudo portuguesas e a criação de um centro de ensino por correspondência, que utilizasse também a radiodifusão, como proposta de construção de um modelo de educação que alcançasse toda a extensão territorial do país e que também não permitisse o envio de divisas, de recursos ao exterior, minando ainda mais as possibilidades de investimento em um sistema educacional nacional.

O resultado disso foi a constituição do Departamento de Ensino à Distância (DED), vinculado ao Instituto Nacional de Desenvolvimento da Educação (INDE) ${ }^{3}$. Inicialmente foram selecionadas 20 pessoas em todo o país para constituírem o primeiro núcleo de especialistas em EaD no país.

O principal produto dessa formação consistiu na elaboração de um curso de formação de professores primários que só possuíam quatro anos do ensino primário — ou seja, que possuíam o mesmo nível formativo ao qual eles estavam ministrando aulas. O objetivo desse curso foi elevar seus conhecimentos ao nível da sexta série do ensino primário e, ao mesmo tempo, garantir-lhes a sua formação psicodidática e pedagógica (NEELEMAN e NHAVOTO, 2003).

\footnotetext{
${ }^{2}$ AfriMAP, é uma iniciativa da Sociedade Civil que visa promover a boa governança na África. É um programa das Fundações Society. Sua função é governança democrática, justa e eficaz em países africanos

${ }^{3}$ INDE é uma instituição pública que se subordina ao Ministério de Educação (MINED), tem como Objetivo principal desenvolver pesquisas no âmbito educacional de forma a melhorar a qualidade da educação em Moçambique.
} 
Como proposta didático-pedagógica para a $\mathrm{EaD}$, elaborou-se materiais escritos e programas de rádio, que foram testados, inicialmente, em 1300 professores em exercício de várias províncias do país. A programação obteve grande popularidade, alcançando não só os docentes, mas significativa parte da população. Foram elaborados materiais escritos e programas radiofónicos. Ainda de acordo com os mesmos autores:

\footnotetext{
o grande entusiasmo com que foi lançada esta iniciativa não foi suficiente para sustentá-la no meio de todas as dificuldades que surgiram. O curso arrancou enquanto a formação dos especialistas ainda estava a decorrer, o que resultou frequentemente em atrasos na expedição dos materiais e dos programas radiofónicos. Com o curso ainda na sua fase experimental, o Ministério de Educação decidiu introduzir o novo Sistema Nacional de Educação, alterando os programas e obrigando o curso a reescrever os materiais que acabavam de ser elaborados (NEELEMAN e NHAVOTO, 2003, p. 4).
}

Apesar das iniciativas em EaD, já presentes nas políticas nacionais desde a independência, o obstáculo principal que dificultou ou até mesmo inviabilizou a oferta de cursos a distância no país foi a guerra civil, que cortou as principais redes de comunicação do país, destruiu escolas, além do risco de morte enfrentado pelos professores. A Guerra gerou a interrupção da proposta de formação de professores a distância.

O DED deixou de existir como departamento do INDE, em 1987, e foi integrado no Departamento de Formação em Exercício de Professores do Ministério da Educação. Essa reorganização mostrou que se tinha perdido a perspectiva de educação à distância para todos, que tinha sido a filosofia do DED. Em vez disto, a educação a distância passou a ser uma modalidade apenas na formação continuada dos professores. Grande parte dos originais dos materiais escritos e das bobinas com os programas radiofônicos foram perdidos (NEELEMAN e NHAVOTO, 2003, p. 4).

Como se pode observar, o contexto educacional de Moçambique pouco mudou desde então, pois a guerra só foi cessada em 1992 e este é um tempo relativamente curto para que se possam efetivar transformações educacionais de grande impacto. Para que estas ocorram, sobretudo, precisam de tempo, uma vez que a realização da educação primária e do ensino médio exigem cerca de 12 anos, sem 
contar os tempos necessários para a formação de professores em número adequado à população que necessita.

De acordo com os dados educacionais mais recentes, em 2016 Moçambique possuía cerca de 8 milhões de alunos matriculados na educação primária (primeira à quinta classe), menos de 1,5 milhão na 6 e $7^{\text {a }}$ classes e aproximadamente 460 mil alunos matriculados no último ano ensino secundário. Esses dados demonstram significativas lacunas nas matrículas e nas continuidades escolares, que são relacionadas aos elementos apresentados anteriormente, motivo pelo qual observamos ser importante a discussão acerca do papel da EaD nos processos de adequação idade e tempo de escolaridade no país.

Neste contexto, no âmbito da materialização da Política Nacional da Educação, os diferentes planos estratégicos da Educação desenvolvidos até agora pelo setor têm como finalidade garantir o direito à Educação. Esse direito compreende o acesso universal e equitativo à Educação Básica de crianças, jovens e adultos, assim como a progressiva expansão do acesso ao Ensino Secundário Geral, TécnicoProfissional e Superior. O alcance desta finalidade ainda constitui um grande desafio, tendo em conta o aumento da população escolar nos diferentes níveis (Plano Estratégico de EaD, 2014-2018).

Para se ter uma ideia acerca do desafio posto à educação de Moçambique, a taxa de escolarização bruta no ensino superior da faixa etária entre 18 e 29 anos não chega a $2 \%$ da população, enquanto no Brasil essa taxa ultrapassa os 30\%. Dados do INED/2013 mostram que apenas cinco mil pessoas estudavam cursos superiores a distância, em um universo de cerca de 200 mil alunos matriculados no ensino superior em todo o país. Para efeito de comparação, o Brasil possui cerca de 1/7 dos estudantes do ensino superior matriculados na modalidade a distância, enquanto que em Moçambique essa proporção sobe para 1/40. Já no âmbito dos ensinos primário e secundário, além do desafio de matricular todos, há também um problema recorrente, que é o fato de praticamente $50 \%$ dos jovens matriculados evadirem da escola, o que eleva significativamente o contingente de pessoas sem formação básica. 
Conforme dito anteriormente, as iniciativas governamentais em EaD datam da década de 1980, entretanto, observa-se uma incipiência no que diz respeito à regulamentação da $\mathrm{EaD}$ em Moçambique. A mesma situação é notada no que diz respeito aos profissionais que atuam nessa modalidade, cuja carreira ou reconhecimento da ocupação ainda não existem.

Embora se reconheça o esforço do Governo na promoção desta modalidade de ensino, a situação atual da EaD no País caracteriza-se pela necessidade de uma maior exploração do potencial da modalidade para prover Educação a todos os níveis e tipos de ensino. Os tempos e movimentos de Moçambique acabam por pressionar possibilidades que representem, em curto prazo, melhorias consideráveis nos níveis de escolaridade da população, sobretudo pela velocidade com que as tecnologias digitais vem reconfigurando trabalhos e funções. Ou seja, sem uma formação mínima da população, os riscos econômicos e sociais são iminentes.

\section{Inserção da Educação a Distância nas Instituições de Ensino: Refletindo sobre algumas estratégias}

O desenvolvimento da EaD nos últimos anos, de acordo com Litwin (2001) serviu para implementar os projetos educacionais mais diversos e para as mais complexas situações: cursos para o ensino de ofícios, capacitação para o trabalho ou divulgação científica, campanhas de alfabetização e também estudos formais em todos os níveis e campos do sistema educacional. Arruda (2011), por outro lado, anuncia também o crescimento significativo das iniciativas baseadas em tecnologias digitais contemporâneas que potencializaram o alcance e o número de pessoas ao redor do mundo, estas que se tornam sujeitos dessa modalidade na medida em que tais tecnologias se tornam correntes.

Mombassa e Arruda (2018) indicam ainda que, embora dezenas de países, independentemente do seu grau de desenvolvimento econômico, atendam milhões de pessoas com a $\mathrm{EaD}$ em quase todos os níveis, utilizando sistemas mais ou menos formais (MAIA; MATTAR, 2007, p. 23), muitas pesquisas continuam a revelar que o problema da ineficácia dos programas de EaD reside no fraco envolvimento dos 
governos e na fragilidade das Políticas públicas. Nesse sentido, se de fato os governantes estão cientes da pertinência dessa modalidade de educação para materialização das suas políticas públicas de educação, o primeiro passo a ser dado consiste na reflexão sobre essas questões, visto que constitui objeto central para um país sério e responsável, que deseja se afirmar nacionalmente, regionalmente e internacionalmente.

A dimensão política voltada para o crescimento da $\mathrm{EaD}$ envolve, ainda, estratégias de gestão orientada para a promoção e desenvolvimento de práticas de organização e gestão das unidades de $\mathrm{EaD}$, que são processos de liderança e coordenação que devem ser desencadeadas ao nível das instituições provedoras dessa modalidade de educação. Zawacki-richter e Anderson (2015) destacam a liderança e a coordenação nas organizações como um dos eixos temáticos que deve ser considerando e, cada vez mais, consolidados, fundamentalmente na área da educação. Isso devido à precariedade da gestão que se verifica em algumas instituições, como também pelo fato de haver uma tendência das instituições de ensino de conduzir na perspectiva das filosofias da gestão empresarial.

No contexto de EaD, a liderança não pode ser equiparada à liderança do ensino presencial, embora a gestão educacional, como bem aponta Mill e Brito (2009), em geral,

\footnotetext{
Baseia-se na administração científica (gestão empresarial), mas guarda certas especificidades que merecem cuidados especiais dos gestores. Por ser uma instituição/empresa de natureza peculiar, as formas de planificar, organizar, dirigir e controlar a escola/universidade precisa ser diferenciado das decisões do gestor empresarial tradicional; pelo tipo de instituição, a gestão da educação superior distingue-se da gestão da educação básica. Da mesma forma, a gestão da EAD deve ser tratada distintamente da gestão da educação presencial (embora suas bases sejam as mesmas) (MILL e BRITO, 2009, p. 7).
}

Para Mill e Brito (2009), o gestor da EaD precisa compreender que a natureza do processo educativo não se confunde com a natureza do processo produtivo e, também, que a natureza do processo educativo virtual (a distância) distingue-se do processo educativo presencial. Uma vez que, “a gestão educacional dessa modalidade também prevê decisões de planejamento, organização, direção e controle semelhantes 
àquelas da educação presencial do ensino superior e também se preocupa com instalações, espaços, tempo, recursos financeiros, informações e pessoas” (MILL e BRITO, 2009).

Para que a EaD esteja bem concebida e enraizada em todos os departamentos e centros de ensino da instituição, conforme Mill e Brito (2009) apontam, o desafio está na mudança de mentalidade de toda a comunidade universitária em prol de uma EaD efetiva, o que exige um trabalho descentralizado e participativo na capitalização das discussões entre os sujeitos em seus respectivos setores institucionais. Ou por outra, segundo os autores, a implementação da EaD, com vistas à convivência harmónica e integral inter-relacionada com a educação presencial, exigindo mudança em toda a estrutura organizacional da instituição, tanto em termos de recursos materiais, humanos, financeiros, informacionais e espácio-temporais. Tudo isso precisa ser bem administrado pelos gestores em suas decisões de planeamento, organização, direcção e controle dos processos (MILL e BRITO, 2009, p. 8).

Os dirigentes também precisam participar do processo político, auxiliando os formuladores de políticas e compreender o potencial da educação à distância, obtendo financiamento e propiciando a mudança da cultura organizacional necessária para a inclusão de métodos de ensino desconhecidos; em virtude de instrutores e alunos estarem distantes da instituição de ensino, devem ser elaborados e mantidos procedimentos especiais para o recrutamento, o acompanhamento e a supervisão desses profissionais (MOORE e KEARSLEY, 2007, p. 19).

Portanto, várias são as estratégias que podem ser formuladas para que as atividades de gestão da EaD tenham sucesso. Nesse contexto, percebemos ser necessário que o líder da instituição que oferece a EaD tenha capacidade de transformar a sua organização em organização aprendente ${ }^{4}$.

Neste contexto, com bem destaca Nhavoto, Buendia e Bazo (2009), exige-se dele potencialidades que modifiquem seus processos e práticas de ensinoaprendizagem e, em consequência, a sua estrutura e dinâmica organizacional, o que

\footnotetext{
${ }^{4}$ Sange apud (CANARIO, 2003 ), As organizações que aprendem, segundo são aquelas nas quais as pessoas aprimoram continuamente suas capacidades para criar o futuro que realmente gostariam de ver surgir.
} 
implica dispor desses líderes com novas aptidões cognitivas e atitudinais. Esse é o desafio que emerge para a política educacional moçambicana, para se pensar em uma educação que passe por processos efetivos de democratização e acesso que podem transformar o cenário educacional do país.

\title{
Perspectivas de implementação da EaD em Moçambique como políticas de inclusão
}

Sob uma perspectiva de se tentar modificar a situação educacional de Moçambique, observamos a construção do Plano Estratégico da Educação (20122016) como uma das ações para o desenvolvimento da educação. Este documento apresenta uma abordagem política integrada, com uma visão estratégica sólida e a um referencial de ação, que pretendeu articular e mobilizar os ecossistemas de financiamento e de implementação em torno de uma estratégia cuja implementação vai promover não só a melhoria do sistema de ensino, mas também o desenvolvimento económico e social (MOÇAMBIQUE, 2012, p. 51).

Conforme acordos previstos no acordo ratificado em Acra, em $2008^{5}$.

\begin{abstract}
A avaliação do PEEDH notou que, embora se verifiquem progressos no uso de TICs como um instrumento de apoio à gestão ao nível do Ministério, das DPECs e até mesmo em alguns distritos já eletrificados, a sua integração no currículo como meio do ensino e de comunicação é ainda limitada. E as maiores dificuldades, de acordo com este documento foram sentidas em termos de disponibilidade de infraestruturas adequadas, na falta de manutenção dos computadores e insuficiência de verbas para manter operacionais as salas de informática (MOCAMBIQUE, 2012, p. 51).
\end{abstract}

No Ensino Superior, algumas limitações descritas acima foram corroboradas por alguns pesquisadores envolvidos nos programas de EaD em Moçambique. Por exemplo, Brito (2010) evidenciou que a maioria dos programas enfrentava a falta de continuidade e a falta de recursos humanos capacitados para atuarem na modalidade. De igual modo, os problemas constatados por Brito também foram evidenciados por Chovano (2012) e Mombassa (2013), embora com alguma diferença. Enquanto que Chovano (2012, p. 259) percebeu que, a maior parte dos professores não reunia

\footnotetext{
${ }^{5}$ Agenda promove a eficiência e a eficácia da ajuda com o objetivo principal de reduzir os custos de transação da ajuda externa para os países recipientes e melhorar o impacto no seu desenvolvimento.
} 
competências para utilizar algumas ferramentas tecnológicas como, por exemplo, a plataforma, Skype, blogues, Facebook, Youtube, entre outras. Mombassa (2013) constatou que os problemas inerentes à utilização das tecnologias estavam associados à falta de uma estrutura organizacional que tivesse a capacidade de dar suporte permanente ao alunos, professores e gestores, como também fragilidade das lideranças da gestão da modalidade.

Para compreender a importância da inserção de EaD nas instituições de educação em Moçambique, outro dado relevante diz respeito à evolução de instituições de Ensino Geral (EG) e Ensino Superior (ES) e os números de estudantes de ES matriculados por província. Dados divulgados pelo Governo de Moçambique (2015) apontam que o EG tem crescido exponencialmente, embora possa constatarse que essa realidade no sistema está além das suas capacidades de prover uma educação de qualidade para todos. E a mesma situação ocorre no ES. Pesquisas do Ministério de Educação e Desenvolvimento Humano (MINEDH) e Ministério das Ciências e Tecnologias Ensino Superior e Ensino Técnico Profissional (MCTESTP), nos últimos cinco anos (2013-2017) apontam que, nos dois subsistemas de ensino referenciados, o número de escolas existentes continuam não satisfazendo a demanda. Haja vista que dados do levantamento educacional de 2017 demonstram que há uma razoável discrepância entre os efetivos escolares (escolas) do ensino primário do $1^{\circ}$ grau ( $1^{\mathrm{a}}$ a $5^{\mathrm{a}}$ séries) e os demais níveis. Há $72 \%$ de escolas destinadas ao ensino primário de $1^{\circ}$ grau, em contraponto a $13,1 \%$ destinados ao ensino primário de $2^{\circ}$ grau ( $6^{\mathrm{a}}$ e $7^{\mathrm{a}}$ series). O ensino médio fica com taxas ainda menores, sendo 10,3\% destinados ao primeiro ciclo) e 3,9\% ao segundo ciclo. Nota-se, portanto, que existem, somente nas faixas etárias correspondentes aos níveis educacionais esperados no país, aproximadamente sete milhões de moçambicanos que descontinuam a sua formação em nível básico.

Os mesmos dados demonstram que é ainda desafiador formar professores para atender toda a demanda, haja vista que gira em torno de 60 alunos por professor no país. Ou seja, uma das possibilidades a curto prazo apresenta-se com a indução da 
EaD como forma de diminuir tempos e espaços de formação da população, de forma a reduzir as desigualdades educacionais internas e externas.

Ao se observar os dados educacionais de Moçambique, é possível afirmar que a oferta de programas de EaD podem significar passos importantes para promover a inclusão educacional, social e econômica de grande parte da população, o que pode ser um passo significativo rumo à redução das assimetrias regionais ${ }^{6}$. Também, pelo fato do ensino secundário e do ensino superior constituirem subsistemas estratégicos para o desenvolvimento da classe trabalhadora no país, torna-se necessário consolidar as estrategias de alinhamento da políticas públicas voltadas para EaD nos dois subsistemas, uma vez que muitos estudantes não possuem condições de ingressar no ensino superior, devido ao fato dele ser pago, mesmo em instituições públicas.

Apesar das altas taxas de transição entre o Ensino primário 2 e o Ensino secundário geral 1 (da $7^{\mathrm{a}}$ para a $8^{\mathrm{a}}$ classe) e entre o Ensino secundário geral 1 e ensino secundário geral 2 (da $10^{\mathrm{a}}$ para a $11^{\mathrm{a}}$ classe) (incluindo os turnos diurno e noturno e os ensinos públicos, privado e comunitário), o número de jovens que não frequentam as escolas secundárias por não terem concluído a $7^{\mathrm{a}}$ classe ou por terem desistido ao longo da escola secundária é elevado, situação que continuará ao longo dos próximos cinco anos. Isto implica a necessidade de oferecer alternativas para este grupo alvo por via da expansão do ensino profissional e da oferta de cursos de curta duração, sobretudo na modalidade EaD (MOCAMBIQUE, 2012).

Ainda sobre a inserção de EaD nas instituições de ensino, vale refletir sobre o número de alunos matriculados no ES segundo o MCTESTP (2012-2017), em 2013, foram matriculados naquele subsistema de ensino cerca de 128.073 alunos; em 2014, 157.431; em 2015, 174.802; em 2016, 196.801. Se considerarmos uma população de aproximadamente 25 milhões de habitantes, temos, portanto, menos de 1\% dos habitantes matriculados no ensino superior, o que representa uma significativa

\footnotetext{
${ }^{6} \mathrm{~A}$ introdução das TIC no sistema de ensino, apoiada por conteúdos digitais direcionados para a população moçambicana, visa acelerar a alfabetização e a info-inclusão, contribuindo simultaneamente para esbater as assimetrias regionais, entre as populações urbanas e rurais e entre homens e mulheres. Disponível em: $<$ http://www.mined.gov.mz/Legislacao/Documents/Plano_Tecnologico_Educacao_1a_versao.pdf>. 
exclusão social que impacta sobremaneira no crescimento econômico, social e cultural do país.

Ao relacionar esses dados com o número de alunos de ES matriculados por província, observa-se que Maputo (capital de Moçambique) continua sendo a região com maior número de estudantes que ingressam naquele subsistema de ensino (Tabela 3). No nosso entendimento, como resposta a essa desigualdade de oportunidades, a EaD, constitui mais um motivo para as instituições públicas e privadas repensarem nas suas políticas institucionais.

Para um país em que cerca de $70 \%$ da maioria da população reside na área rural e estimativa da população total moçambicana, de acordo com Instituto Nacional de Estatística (MOÇAMBIQUE, 2017), ser de 28.8 milhões de habitantes, assim como a população adulta representa $52 \%$, seguido dos jovens com $45 \%$, a EaD deve constituir a maior aposta dos gestores das universidades para os próximos anos (MOÇAMBIQUE, 2015b).

Dados do Ministério da Educação de Moçambique (MOÇAMBIQUE, 2015b) demonstram que a maior parte das instituições que oferecem os cursos na modalidade a distância são instituições privadas, e os cursos oferecidos pelas instituições públicas estão voltados para Ciências Sociais e Humanas em detrimento das Ciências Aplicadas 7 . Isso nos leva a questões acerca da importância dada à EaD como política pública de formação no país, e demonstra que existe um longo e importante caminho a ser trilhado para que seja possível a implementação de grandes programas educacionais em $\mathrm{EaD}$ que atendam a população moçambicana.

Existem, no total, 10 IES que oferecem cursos superiores na modalidade EaD: Universidade pedagógica (UP), Universidade Eduardo Mondlane (UEM), Academia

\footnotetext{
${ }^{7}$ Por exemplo, a Universidade Eduardo Mondlane, atualmente, oferece o curso de Licenciatura em Organização e Gestão da Educação, Licenciatura em Gestão de Negócios e Licenciatura em Administração Pública (PORTAL DA UNIVERSIDADE EDUARDO MONDLANE, 2018). E a UP conta com 10 cursos na modalidade à distância, a saber: curso de Licenciatura em Ensino de Inglês; curso de Licenciatura em Administração e Gestão de Educação; curso de Licenciatura em Ensino Básico; curso de Licenciatura em Ensino de Química; curso de Licenciatura em Ensino de Matemática. Curso de Licenciatura em Ensino de Biologia; curso de Licenciatura em Ensino de Química; curso de Licenciatura em Ensino de Física; e curso de Licenciatura em Informática Aplicada (PORTAL DA UNIVERSIDADE PEDAGOGICA, 2018).
} 
de Ciências Policiais, Instituto Superior de Administração Pública, Universidade Católica de Moçambique, Instituto Superior Monitor, Instituto Superior Dom Bosco, Universidade A Politécnica, Instituto Superior de Tecnologia e Educação e Instituto Superior de Ciências e Educação a Distância. Dessas, 3 são públicas: a Universidade Eduardo Mondlane, a Universidade Pedagógica e o Instituto Superior de Administração Pública.

Ao considerarmos o número total de alunos matriculados no ensino superior, dos 196.801, apenas cinco mil estão matriculados na modalidade a distância, ou seja, apenas 2,5\% da população universitária de Moçambique. Não há dados consolidados que demonstrem o universo de alunos matriculados na modalidade a distância na educação primária e na educação secundária, o que nos leva a crer que são ainda mais baixos.

De acordo com Mombassa e Arruda (2018), as dificuldades de implementação e expansão da EaD em Moçambique reside na desconfiança na modalidade, ainda existente nas instituições e seus sujeitos, bem como os financiamentos limitados que são alocados a instituições públicas. Compreender esses problemas e discutir perspectivas emergem como principais questões futuras para se pensar na $\mathrm{EaD}$ em sua dimensão inclusiva na educação de Moçambique.

Ainda segundo os autores, como forma a responder às demandas de $\mathrm{EaD}$, o governo Moçambicano, igualmente, reconhecendo que a EaD já é uma prática em Moçambique e o papel importante que esta pode ter na massificação e equidade no acesso à formação, através da possibilidade de repartição dos recursos humanos, financeiros e materiais de qualidade por um número maior de beneficiários, e havendo necessidade de ampliar a oferta educativa, bem como regulamentar o funcionamento do ensino à distância, aprovou o decreto número 35/2009 de 7 de julho que guia-se pelos seguintes princípios: a) Acesso à educação como direito e dever do cidadão; $b$ ) Paridade entre as modalidades presencial e à distância; c) Equidade regional, social e de género; d) Racionalização no uso de recursos e infraestruturas; e) Articulação entre os diferentes níveis de ensino e entre instituições públicas e privadas. 
Ao se considerar a dimensão da Política Nacional da Educação, os diferentes planos estratégicos desenvolvidos em Moçambique têm como finalidade garantir o direito à Educação e a inclusão do maior número possível da população. Esse direito compreende o acesso universal e equitativo à Educação Básica de crianças, jovens e adultos assim como, a progressiva expansão do acesso ao Ensino Secundário Geral, Técnico-Profissional e Superior. O alcance desta finalidade ainda constitui um grande desafio, tendo em conta o aumento da população escolar nos diferentes níveis (Plano Estratégico de EaD, 2014-2018).

Embora se reconheça o esforço do Governo na promoção desta modalidade de ensino, a situação atual da EaD no País caracteriza-se pela necessidade de uma maior exploração do potencial da modalidade para prover Educação a todos os níveis e tipos de ensino.

Apesar dos baixos números e das dificuldades atuais para oferta da EaD, percebe-se que há um potencial imenso de crescimento da EaD que, possivelmente, representaria um grande salto educacional e inclusivo a Moçambique, conforme temos afirmado ao longo desse trabalho.

\section{Considerações finais}

A Educação a distância é uma modalidade que potencializa a inclusão social, educacional, econômica e cultural de um país, sobretudo nas condições de Moçambique, recém-saído de conflitos civis e com um patamar de alfabetização extremamente baixo, além de grande parte da população ser analfabeta.

No que tange ao investimento em educação presencial, há uma quase impossibilidade em curto prazo, devido a necessidade de se promover crescimento contínuo de infraestrutura, de profissionais formados e recursos financeiros atualmente indisponíveis ao governo de Moçambique.

A EaD emerge, nesse contexto, como uma possibilidade real de ampliação do acesso à educação, sobretudo a educação superior em curto prazo e uma possibilidade para a educação primária e secundária. 
Entretanto, o país ainda se encontra em uma situação delicada, pois os investimentos feitos em EaD encontram-se razoavelmente aquém do crescimento necessário para que a ampliação da educação de Moçambique tenha maior efetividade.

Nesse trabalho observamos os desafios que ainda são postos a Moçambique para que haja inclusão por meio do acesso à educação. A EaD emerge como condicionante para que essa inclusão possa ser ampliada ao maior número possível de pessoas, sobretudo porque Moçambique encontra-se em situação precária, mesmo frente a outros países Africanos.

Considerar a inclusão envolve um comprometimento com o acesso à educação e, por conseguinte, acesso da população a elementos que deveriam ser básicos em sua sobrevivência, como saúde, melhores condições de vida e de interpretação do mundo. A EaD, portanto, é um imponente meio de promover crescimentos em toda Moçambique.

\section{Referências}

ARRUDA, Eucidio Pimenta. Aprendiragens e jogos digitais. São Paulo: Alinea Editora, 2011.

BRITO, L. Discurso político e pobreza em Moçambique: análise de três discursos presidenciais. In L. BRITO, C. N. Castel-Branco; S. Chichava e A. Francisco (orgs.) Pobreza, Desigualdade e Vulnerabilidade em Moçambique. IESE: Maputo, 2010.

CHOVANO, L. S. H. de. Desenvolvimento profissional docente para o ensino à distância na Universidade Eduardo Mondlane. Tese (Doutorado em Multimídia em Educação) Universidade de Aveiro, Portugal, 2012. Disponível em: <http://hdl.handle.net/10773/9603>. Acesso em: 06 jul. 2018.

HANLON, Joseph. Paz sem Benefícios: Como o FMI Bloqueia a Reconstrução de Moçambique, coleção nosso chá no 10, Livraria Universitária, $1^{a}$ edição, Moçambique, 1997.

LITWIN, E. (org.). Educação a Distância: Temas para debate de uma nova agenda. Porto Alegre: Artmed Editora, 2001.

MAIA, C.; MATTAR, J. Abc da EaD: educação a distância hoje. $1^{a}$ ed. São Paulo: Pearson Prentice Hall, 2007.

MILL, D.; BRITO, N. D. Gestão da Educação a distância: origem e desafios. São Carlos / ABED. São Paulo: São Carlos, 2009. Disponível em: <http://www2.abed.org.br/congresso2009/CD/trabalhos/652009145737.pdfhttp://www 
.ufsj.edu.br/portal2-repositorio/File/vertentes/Vertentes_35/daniel_mill_e_outros.pdf>. Acesso em: 05 jan. 2019. Acesso em: 29 set. 2017.

MOÇAMBIQUE. Ministério de Educação e Desenvolvimento Humano. Política Nacional de Educação (Resolução n.8/95). Boletim da República, Serie n. I, n.41, 22 de Agosto de 1995.

MOÇAMBIQUE. Ministério de Educação e Desenvolvimento Humano (MINED). Levantamento estatístico de alfabetização. 2010. Disponível em: <http://www.mined.gov.mz/STATS/Pages/15Marco.aspx>. Acesso em: 06 abr. 2018.

MOÇAMBIQUE. Ministério de Educação e Desenvolvimento Humano. Plano estratégico de Educação: 2012-2016. Maputo, 2012. Disponível em: $<$ http:/ /www.mept.org.mz/index.php?option=com_docman\&task=doc_view\&gid=79\&It emid=48>. Acesso em: 4 abr. 2018.

MOÇAMBIQUE. Plano Estratégico do Ensino Superior 2012-2020. Imprensa Universitária, 2012.

MOCAMBIQUE. Dados Estatísticos sobre o Ensino Superior em Moçambique. 2013. Disponível em: <http://www.mctestp.gov.mz/sites/default/files/doc/estat2013.pdf>. Acesso em: 7 de jul. 2018.

MOÇAMBIQUE. Dados Estatísticos sobre o Ensino Superior em Moçambique. 2014. Disponível em: <http://www.mctestp.gov.mz/sites/default/files/sites/default/files/doc/Dados\%20Estat isticos\%202014.pdf> Acesso em: 7 de jul. 2018.

MOÇAMBIQUE. Ministério de Educação e Desenvolvimento Humano. Estratégia de Educação a Distância: 2014-2018. Maputo, 2014. Disponível em: <http://www.mined.gov.mz/IST/IEDA/Documents/Estrat\%C3\%A9gia\%20EAD.pdf>. Acesso em: 4 abr. 2018.

MOÇAMBIQUE. Instituto Nacional de Estatística. Anuário Estatístico 2015. Maputo: Instituto Nacional de Estatística, 2015a.

MOÇAMBIQUE. Dados Estatísticos sobre o Ensino Superior em Moçambique. 2015b. Disponível em: <http://www.mctestp.gov.mz/por/content/download/6139/43679/version/1/file/Dado s+Estatisticos+2015.pdf>. Acesso em: 7 de jul. 2018.

MOÇAMBIQUE. Plano Estratégico da Educação. Desempenho do Sector da Educação $2016 . \quad$ Disponível em: $<$ http:/ /www.mept.org.mz/index.php?option=com_docman\&task=doc_view\&gid=91\&It emid=48>. Acesso em: 7 de jul. 2018.

MOÇAMBIQUE. Estatística da Educação. Levantamento Escolar. 2017. Disponível em: $<$ http://www.mined.gov.mz/DN/DIPLAC/Documents/Levantamento\%203\%20de $\% 20$ Marco\%202017.pdf>. Acesso em: 7 de jul. 2018. 
MOÇAMBIQUE. Anuário estatístico da educação. Disponível em: $<$ http://www.ine.gov.mz/estatisticas/publicacoes/anuario/nacionais/anuario-estatistico2016>. Acesso em: 7 de jul. 2018.

MOCAMBIQUE. Programa Quinquenal do Governo (2015-2019). Disponível em: <file://C:/Users/Conecta/Downloads/pqg_2015_2019versaoenviadaar.pdf>. Acesso em: 7 de jul. 2018.

MOÇAMBIQUE. Relatório Sobre os Seis Objectivos da Educação para Todos. Disponível em: <http://unesdoc.unesco.org/images/0023/002317/231723por.pdf> Acesso 07 de jul. 2018.

MOMBASSA, Aires Zarina Bonifácio. A utilização das tecnologias de ensino à distância na Universidade Eduardo Mondlane, Moçambique. Dissertação (mestrado profissional) Universidade Federal de Juiz de Fora, Faculdade de Educação/CAEd. Programa de PósGraduação em Gestão e Avaliação da Educação Pública, 2013. 114 p.

MOMBASSA, A. Z. B. A utilização das tecnologias de ensino à distância na Universidade Eduardo Mondlane, Moçambique. Dissertação (Mestrado em Educação) — Juiz de Fora: Universidade Federal de Juiz de Fora, 2003. Disponível em: $<$ https://repositorio.ufff.br/jspui/handle/ufjf/1463>. Acesso em: 05 jul. 2018.

MOMBASSA, A. Z. B., ARRUDA, E. P. História da Educação a Distância em Moçambique: perspectivas atuais e as contribuições do Brasil. Práxis Educativa. Ponta Grossa: UEPG. v. 13, n. 3, 2018. doi: Disponível em: http://dx.doi.org/10.5212/PraxEduc.v.13i3.0001. Acesso em: 07 jul. 2018.

MOORE, M; KEARSLEY, G. Educação a Distância: Uma visão Integradora. Trad. Roberto Galman. $1^{a}$ Ed. São Paulo: Editora Cengage, 2007.

MOORE, M. G.; PEREIRA, L. F. Avaliação da Rede da Educação à Distância em Moçambique. Projecto de ensino superior submetido ao Ministério da Educação e Cultura. 2007. <http://www.mined.gov.mz/DN/DCI/Documents/INEDdistlearn.pdf>. Acesso em: 02 jan. 2019.

NEELEMAN, W.; NHAVOTO, A. Educação a distância em Moçambique. Revista Brasileira de Aprendizagem Aberta e a Distância, São Paulo, v. 2, p. 1-8, set. 2003. Disponível em:

<http://www.abed.org.br/revistacientifica/Revista_PDF_Doc/2003_Educacao_Distancia _Mocambique_Wim_Neeleman_Arnaldo_Nhavoto.pdf>. Acesso em: 02 jul. 2018.

NGOENHA, S. E. Os Missionários suíços face ao nacionalismo Moçambicano: entre a tsonganidade e a moçambicanidade. Lusotopie, p.425-436, 1999. Disponível em: http://www. lusotopie.sciencespobordeaux.fr/ngoenha.pdf. Acesso em: Mar. 2019.

HAVOTO, A.; BUENDIA, M. BAZO, M. Direcção e Gestão de escolas promovendo processos de mudança e formação de direcções de escola. Ministério da Educação. Maputo, 2009. 
ZIMBA, H. F.; MULLER, S. P. M. A dimensão política e processo de institucionalização da Ciência e Tecnologia em Moçambique. In: XI ENCONTRO NACIONAL DE PESQUISA EM CIÊNCIA DA INFORMAÇÃO, 11., 2010, Rio de janeiro. Anais... Rio de Janeiro: GT 7 - Produção e comunicação da informação em CT \& I, 2010.

RECEBIDO: $31 / 07 / 2018$

APROVADO: $15 / 02 / 2019$
RECEIVED: 07/31/2018

APPROVED: 02/15/2019
RECIBIDO: $31 / 07 / 2018$

APROBADO: $15 / 02 / 2019$ 